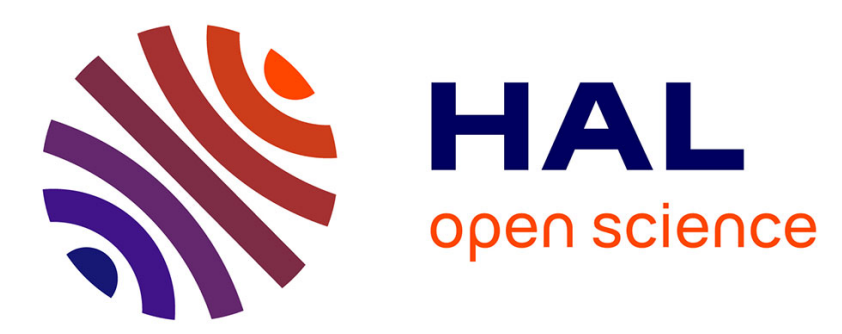

\title{
Osteogenic Sarcoma (Osteosarcoma) in the Elderly: Tumor Delineation and Predisposing Conditions
}

\author{
Consolato Sergi, Werner Zwerschke
}

\section{To cite this version:}

Consolato Sergi, Werner Zwerschke. Osteogenic Sarcoma (Osteosarcoma) in the Elderly: Tumor Delineation and Predisposing Conditions. Experimental Gerontology, 2008, 43 (12), pp.1039. 10.1016/j.exger.2008.09.009 . hal-00499066

\section{HAL Id: hal-00499066 https://hal.science/hal-00499066}

Submitted on 9 Jul 2010

HAL is a multi-disciplinary open access archive for the deposit and dissemination of scientific research documents, whether they are published or not. The documents may come from teaching and research institutions in France or abroad, or from public or private research centers.
L'archive ouverte pluridisciplinaire HAL, est destinée au dépôt et à la diffusion de documents scientifiques de niveau recherche, publiés ou non, émanant des établissements d'enseignement et de recherche français ou étrangers, des laboratoires publics ou privés. 


\section{Accepted Manuscript}

Osteogenic Sarcoma (Osteosarcoma) in the Elderly: Tumor Delineation and Predisposing Conditions

Consolato Sergi, Werner Zwerschke

PII:

S0531-5565(08)00299-4

DOI:

10.1016/j.exger.2008.09.009

Reference:

EXG 8549

To appear in:

Experimental Gerontology

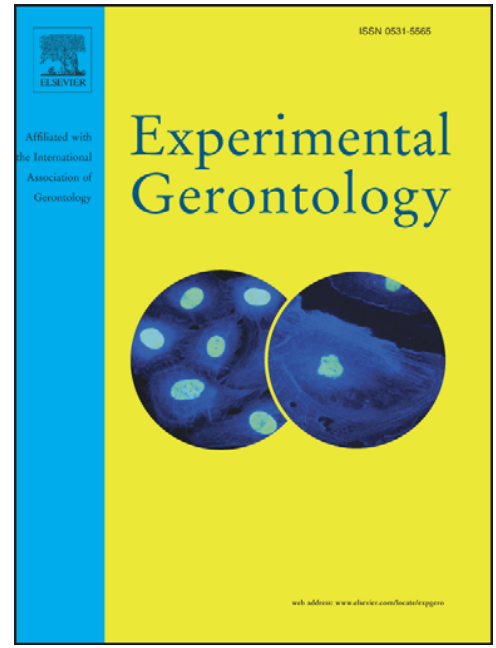

Received Date: $\quad 25$ February 2008

Revised Date: $\quad 2$ September 2008

Accepted Date: $\quad 11$ September 2008

Please cite this article as: Sergi, C., Zwerschke, W., Osteogenic Sarcoma (Osteosarcoma) in the Elderly: Tumor Delineation and Predisposing Conditions, Experimental Gerontology (2008), doi: 10.1016/j.exger.2008.09.009

This is a PDF file of an unedited manuscript that has been accepted for publication. As a service to our customers we are providing this early version of the manuscript. The manuscript will undergo copyediting, typesetting, and review of the resulting proof before it is published in its final form. Please note that during the production process errors may be discovered which could affect the content, and all legal disclaimers that apply to the journal pertain. 


\section{MINI-REVIEW}

OSTEOGENIC SARCOMA (OSTEOSARCOMA) IN THE ELDERLY: TUMOR DELINEATION ANd Predisposing Conditions

Consolato Sergi ${ }^{1-2}$, Werner Zwerschke ${ }^{3}$

${ }^{1}$ Institute of Pathology, Medical University of Innsbruck, Austria

${ }^{2}$ Department of Laboratory Medicine, University of Alberta, Canada

${ }^{3}$ Cell Metabolism and Differentiation Research Group, Institute for Biomedical Aging Research of the Austrian Academy of Sciences, Innsbruck, Austria

\section{Running title: Osteogenic Sarcoma in the Elderly}

\section{Address for Correspondence}

Consolato Sergi, $\mathrm{MD}, \mathrm{PhD}$

Institute of Pathology

Medical University of Innsbruck

Muellerstrasse 44, AT-6020 Innsbruck, Austria

Tel.: +435129003 71316

Fax: +43512582088

E-mail: biotechlab@gmail.com 


\begin{abstract}
Osteogenic sarcoma (OS), the most common primary bone cancer, is conventionally a primary intramedullary (conventional OS) high grade malignant tumor characterized by malignant cells forming immature bone or osteoid. The age distribution data for primary bone sarcomas are bimodal. OS is largely a disease of the young but about one third of OS occurs in patients over 40 years of age. Thus, though considered as rare occurrences, bone tumors occur also in the geriatric population. In this report, tumor delineation and the significance of predisposing conditions to the occurrence of OS are reviewed.
\end{abstract}

Key Words: osteosarcoma, elderly, predisposition 


\section{Definition, Epidemiology and Sites of Involvement}

Osteogenic sarcoma (OS) is conventionally a primary intramedullary (conventional OS) high grade malignant tumor characterized by malignant cells forming immature bone or osteoid. There are a number of synonyms that mostly refer to histologic variants $\left({ }^{1}\right)$. OS is the most common, non-hematopoietic, primary malignant tumor of bone with an estimated incidence of 3 cases per million of population per year $\left(^{2}\right)$. There is no significant association to a particular ethnic group or race. OS is largely a disease of the young. In fact, in about $60-75 \%$ of cases, patients with osteosarcoma are between $15-25$ years of age. However, in about one third of OS patients over 40 years of age are affected. Some literature data would indicate that OS can also be found in older patients and particularly with Paget disease of bone, post-radiation sarcoma and dedifferentiated chondrosarcomas, which is the second most common primary bone cancer, but actually no strong conclusions can be drawn due to few small series reports and mostly case reports specially for radiation and chondrosarcoma) $\left(^{3-4-5-6}\right)$. Thus, clinico-pathological and cell biology studies on OS are intensely strengthening the research platform and probably will be extremely important to better clarify the nature of this very intriguing tumor. Conventional OS has a predilection for male gender (male: female $=3: 2$ ), although this selection tends to become even with increasing age. OS occurs in the long tubular bones of the appendicular skeleton in $80-90 \%$ of cases and distal femur, proximal tibia and proximal humerus account for about $85 \%$ of extremity tumors, while less than $1 \%$ are found in hands and feet bones $\left(^{7}\right)$. OS originating in the mid-shaft are uncommon and these originating in the epiphysis are very rare. The relative incidence in non-long 
bone involvement, including jaws, pelvis, spine and skull, tends to increase in geriatric age.

\section{Clinics, Imaging, Histology and Staging}

Most patients who present with OS of the appendicular skeleton complain of pain prior to soft tissue swelling. Pain is often due to stretching of the periosteum and is described as deep and severe and may frequently wax and wane or may be due to minute stress fractures. Systemic symptoms include weight loss, pallor, fever, anorexia, but they are very uncommon.

The interaction of OS with the periosteum may lead to a variety of manifestations secondary to periosteal elevation (e.g. Codman's triangle). Computer tomography (CT) scan and magnetic resonance imaging (MRI) help in delineating the extent of the tumor for pre-operatively staging, whereas Tm99 radionuclide bone scan usually provides valuable information with reference to "skip-metastases", i.e. non-contiguous intramedullary growth within the parent bone or across adjacent bones. Since OS is a hypervascular lesion, arteriography can be used to get important information for the surgeon and clinician with regard to tumor response, or lack of response, and to preoperative therapy.

OS is frequently a large fleshy or hard tumor, which is metaphyseally centered with a tendency to transgress the cortex and growth as a soft tissue mass. OS can also produce varying amount of cartilage and / or fibrous tissue and macroscopy appearance is often 
correlated to the more or less presence of bone or cartilage forming malignant tissue.

Thus, more bone-forming OS may appear grey-tan and sclerotic, whilst cartilage forming

OS may appear white-tan with a fish-flesh or rope-like cut surface. World Health

Organization (WHO) histologic classification of bone tumors divides OSs into central

and surface tumors, and recognizes a number of subtypes within each group. To confirm

diagnosis, a biopsy is always required and may be very challenging for the pathologist.

Osteosarcoma is defined as a mesenchymal tumor constituted by neoplastic cells (cells

with atypias) producing a variable amount of immature bone tissue (osteoid). Both

conditions have to be present for the diagnosis of osteosarcoma. The tumor cells may be epithelioid, plasmacytoid, fusiform, ovoid, round, clear, multinucleated, and spindle. In most cases, there is a mixture of two or more of these cell types. However, OS can also produce varying amount of cartilage and/or fibrous tissue and OS can be subdivided in terms of the predominant matrix, including osteoblastic OS (50\%), chondroblastic (25\%), and fibroblastic (25\%). Unusual histological forms include osteoblastic osteosarcoma sclerosing type, osteoblastoma-like osteosarcoma, chondromyxoid fibroma-like osteosarcoma, chondroblastoma-like osteosarcoma, clear-cell osteosarcoma, malignant fibrous histiocytoma-like osteosarcoma, giant cell rich osteosarcoma, and epithelioid osteosarcoma. All these forms are not associated with a specific biological behavior that differs from conventional osteosarcoma. Consequently, all these lesions are viewed as forms o subtypes of conventional osteosarcoma. There are other forms, including the telangiectatic osteosarcoma, which is particularly sensitive to chemotherapy, but this may not reflect an improved survival, and the small cell osteosarcoma, which has a slightly worse prognosis than conventional osteosarcoma (Figure 1a-d). 
It is advisable that biopsy material is obtained by the use of either a large core tissue biopsy or, preferably, by an open biopsy. As stated above, the accurate identification of osteoid is essential. Osteoid is a dense, pink, amorphous intercellular material to be distinguished from fibrin, amyloid and non-osseous collagen. This latter material tends to be linear, fibrillar, and compresses between neoplastic cells, whilst osteoid is curvilinear with small nubs, arborization, and forming abortive lacunae. Bony matrix is sometimes very thin (so called "filigree" pattern) and has a tendency to growth by appositional deposition upon previously existing normal bone trabeculae (so called "scaffolding" pattern). Immunohistochemistry is mostly important to exclude metastastic sarcomatoid carcinoma and synovial sarcoma that express antigens of the intermediate filaments of the cytoskeleton (cytokeratins). Antibodies against osteocalcin and osteonectin are useful in highlighting immature bone tissue $\left({ }^{8-9}\right)$. Osteocalcin is a vitamin $\mathrm{K}$-dependent matrix protein that contains g-carboxyglutamic acid. This protein strongly inhibits calcium salt precipitation and shows a strong affinity for hydroxyapatite, but inhibits crystal growth by delaying nucleation, and normally limits bone formation. Osteonectin or BM40, is a secreted calcium binding protein involved in bone development that demonstrates affinity for hydroxyapatite and collagen. Osteonectin shows a counteradhesive effect on vitronectin-induced adhesion and is involved in lowering the adhesiveness of tumor cells, thus increasing their invasive properties. Osteonectin is also able to inhibit proliferation of endothelial cells and fibroblasts $\left({ }^{10}\right)$. 
The currently used Musculoskeletal Tumor Society staging system is reported in Table 1 $\left({ }^{11}\right)$.

\section{Osteosarcoma occurring in Paget disease, post-radiation site and dedifferentiated chondrosarcoma}

OS is largely a disease of the young, but about one third of OS occurs in patients over 40 years of age and can be found in older patients probably also with predisposing conditions. Thus, the geriatric population has to be carefully observed. Although facts are missing in the literature, it has been emphasized that Paget disease of bone (also called osteitis deformans), originally described by Sir James Paget in $1877\left({ }^{12}\right)$, might be an important predisposing condition $\left({ }^{13-14-15}\right)$. In fact, sarcomatous transformation is a rare but deadly complication of Paget disease of bone. However, since the rarity of these cases require a particular attention in drawing easily conclusions and further studies are necessary, particularly now in the era of neo-adjuvant chemotherapy $\left({ }^{16-17}\right)$. Paget disease of bone is a chronic skeletal disorder that affects up to $2-3 \%$ of the population over the age of 60 years and is primarily a disease of the osteoclast $\left({ }^{18}\right)$. The pathologic abnormality in patients with Paget disease involves increased bone resorption by the osteoclasts, followed by abundant new bone formation that is of poor quality. Practically, there is a disruption of normal bone remodeling $\left({ }^{19}\right)$. Excessive lysis and bone formation result in the "mosaic" pattern of lamellar bone seen histologically and account for the increased susceptibility to bony fracture. The disease may show a monostotic or polyostotic pattern, and most patients are asymptomatic. Genetic linkage analysis indicated that $40 \%$ of patients with Paget disease of bone have an affected first degree 
relative and $1 \%$ of patients develop sarcomatous degeneration of pagetic bone tissue, which is the most serious complication of Paget disease of bone $\left({ }^{20}\right)$. Paget sarcoma is considered a rare malignant entity, but it has to be kept in mind in investigating elderly people with extensive Paget disease. A detailed retrospective study of 43 patients with Paget sarcoma (16 patients found in the Dr. Henry L. Jaffe Pathology Collection treated from 1942 to 1967 and 27 patients treated for the disease by the Harvard Orthopaedic Oncology Group from 1972 to 2001) have been performed by Mankin and Hornicek $\left({ }^{21}\right)$. The primary sites of occurrence were the pelvis, proximal femur, proximal humerus, and calvarium. At the time of diagnosis, patients often presented with metastases and survival rate was very poor. Three tumors were characterized by giant cells, which are occasionally found in patients with florid Paget disease but are not malignant. One third of the patients affected with OS presented with as stage III tumors and their rate of survival was $14 \%$ at approximately 2.5 years. With reference to survival rate there was an astonishing concordance in the patients treated between 1946 and 1967 and those treated between 1972 and 2001. A little progress has occurred in the treatment of Paget sarcoma over the years, which is in pointed contrast with the relatively more favorable statistics for conventional OS of the young. Multifocal sarcomatous degeneration of Paget disease of bone has also been described $\left({ }^{22}\right)$. Although uncommon, it occurs mainly in polyostotic Paget disease and can arise in any skeletal site. In many cases, it remains unclear if these cases are due to the simultaneous development of several primaries or to metastases from a single primary neoplastic lesion. 
Post-radiation osteosarcoma is also a further event of osteosarcoma of the elderly. In a series of 39 irradiated conventional giant cell tumors of bone located in the vertebrae and pelvic bones where debulking surgery was not possible and the tumors were pressing on the spinal cord, five patients developed sarcomas of which one was an osteosarcoma $\left({ }^{23}\right)$. All the patients developing post-radiation sarcomas died within a few months due to lung metastasis prompting for a tight follow-up. Post-radiation sarcoma is a late complication of radiotherapy and should be keept in mind in localizations where radiotherapy is particularly efficacious such as laryngeal carcinoma. Post-radiation osteosarcoma is the most common type of sarcoma arising in patients with laryngeal cancer or other head and neck malignancy undergoing radiotherapy $\left({ }^{24}\right)$.

Finally, another condition which can be considered predisposing to the development of OS is dedifferentiated chondrosarcoma $\left({ }^{25}\right)$. This tumor can occur even 20 years after the initial diagnosis of chondrosarcoma, as reported in a 47-year-old woman $\left({ }^{26}\right)$. In a French study of 13 dedifferentiated chondrosarcomas at Cochin Hospital, Paris, the authors found five OS with an average survival time of nine months $\left({ }^{27}\right)$.

\section{Differential Diagnosis}

Chondrosarcoma are additional types of bone tumors with increasing incidence in the elderly $\left({ }^{28-29-30}\right)$. Chondrosarcoma develops from the cartilage of bones and is the second most common primary bone cancer $\left({ }^{31}\right)$. This cancer occurs rarely in patients younger than 30 years, and the risk of developing chondrosarcoma continues to rise until reaching about 75 years. Men and women are equally likely to get this cancer. Cartilage is made of 
a fibrous tissue matrix mixed with a gel-like substance. First cartilage develops and then calcium compounds are deposited to form bone. Most of the cartilage in a developing bone eventually becomes bone. But cartilage will remain at the ends of the bone where it acts as a cushion between bones. Cartilage is mainly found at the end of long bones and at the place in the chest where the ribs meet the sternum. Cartilage is also part of the face. Other structures that contain cartilage are the trachea and larynx. Chondrosarcomas can develop in any of these places. Most develop in bones such as the pelvis, leg bone or arm bone. Occasionally, chondrosarcoma will develop in the trachea, larynx, and chest wall. Other sites are the scapula, ribs, or skull. Chondrosarcomas are classified into three grades. Most chondrosarcomas are low grade (grade I), meaning they are not likely to spread, or intermediate grade (grade II). High grade (grade III) chondrosarcomas, which are the most likely to spread, are less common. Dedifferentiated chondrosacromas start out as typical chondrosarcomas but then some parts of the tumor change into cells that closely resemble those of an osteosarcoma or fibrosarcoma. This variant of chondrosarcoma tends to occur in older patients and is more aggressive than usual chondrosarcomas. Finally, clear cell chondrosarcoma is a rare variant that grows slowly and rarely spreads to other parts of the body unless it has already recurrent several times in the original location.

Fibrosarcoma and malignant fibrous histiocytoma develop more often in soft tissues, such as ligaments, tendons, fat, and muscle, but can rarely start in bones $\left(^{32}\right)$. When malignant fibrous histiocytoma develops in bones, it usually affects the legs or arms. This cancer is rare among children and occurs with highest incidence in adults in the fifth and sixth 
decades and in the elderly $\left({ }^{33}\right)$. Malignant fibrous histiocytoma tends to grow quickly and to spread to other parts of the body. Fibrosarcoma is another type of cancer that usually occurs in middle-aged adults and the elderly $\left({ }^{34}\right)$. Bones most often affected include those of the legs, arms, and jaw.

\section{Therapy Options and Conclusive Remarks}

Improving cure rates for OS continues to be a major challenge. Surgical excision of the OS is the treatment of choice when it is possible and both radiation therapy and chemotherapy have largely an adjuvant and essential role $\left({ }^{35-36}\right)$. Whereas no other treatment but surgery is currently available for cartilage-forming malignant bone tumors, osteosarcomas show an approximately 50-80\% response rate to adjuvant chemotherapy and surgical removal of these tumors may currently be performed with limb salvage (removal of the malignant bone tumor without amputation, and replacement of bones and joints with allografts or prosthetic devices) $\left({ }^{37}\right)$. The clinical management of patients with OS is very demanding and requires a skilled, experienced team including a surgeon, pathologist, oncologist, and radiologist, with support from specialist nurses and rehabilitation teams. Outcomes from treatment have improved little in 20 years and remain disappointing. An aspect to be considered is that elderly neoadjuvant therapy might differ from young patients according to renal function. Osteosarcoma usually lacks prognostic markers that could distinguish patients before therapy and drive treatment choices. But recently, the high expression of $\mathrm{CCN} 3$, which are members of a family of cysteine rich matricellular proteins emerging as multifunctional regulators, controlling diverse cellular processes and playing important roles in vascular and skeletal 
development, was significantly correlated with worse prognosis of osteosarcoma $\left({ }^{38}\right)$. Moreover, bcl-2 and Livin, a novel inhibitor of apoptosis protein family member, are highly expressed in osteosarcoma cells and the evaluation of nuclear Livin expression might be a useful prognostic marker in osteosarcoma $\left({ }^{39}\right)$. We previously demonstrated that ubiquitin/proteasome-dependent proteolysis of nuclear insulin-like growth factor binding protein-3 contributes to the avoidance of apoptosis in osteosarcoma cells $\left({ }^{40}\right)$. Clinical studies are on progress to evaluate the possibility to interact with the natural history of osteosarcoma acting on the ubiquitin/proteasome-dependent proteolysis of nuclear insulin-like growth factor binding protein-3. Currently, chemotherapy for osteosarcoma is among the most exhausting of any given for solid tumors, and treatment of the primary tumor may be associated with permanent disability of some degree in a significant proportion of patients. Thus, modern treatment programmes are usually multimodal, with surgery combined with both pre- and postoperative chemotherapy. Combined neoadjuvant treatment gives a rate of healing of about $60 \%-70 \%$ for patients with non-metastatic osteosarcoma of the extremities at presentation and of about $30 \%$ for tumors of the axial skeleton $\left({ }^{41-42-43}\right)$. However, radical surgical resection remains crucial for osteosarcoma cure. 


\section{References}

\footnotetext{
${ }^{1}$ Raymond, A.K., Ayala, A.G., Knuutila, S., Conventional Osteosarcoma. In: Tumors of Soft Tissue and Bone. Fletcher CDM, Unni KK (eds). 264-270. World Health Organization Classification of Tumours. Lyon 2002

2 Campanacci, M. Bone and Soft Tissue Tumors: Clinical Features, Imaging, Pathology and Treatment 2nd edition. Wien, Austria: Springer-Verlag; 1999:464-491.

${ }^{3}$ Brooks, S., Starkie, C.M., Clarke, N.M., 1985. Osteosarcoma after the fourth decade. A clinicopathological review. Arch Orthop Trauma Surg 104, 100-5.

${ }^{4}$ Huvos AG. 1986. Osteogenic sarcoma of bones and soft tissues in older persons. A clinicopathologic analysis of 117 patients older than 60 years. Cancer. 57:1442-9.

${ }^{5}$ Huvos AG 1999. Bone Tumors: Diagnosis, Treatment ad Prognosis. $2^{\text {nd }}$ Ed. W.B. Saunders Company.

${ }^{6}$ Deyrup AT, Montag AG, Inwards CY, Xu Z, Swee RG, Krishnan Unni K. 2007. Sarcomas arising in Paget disease of bone: a clinicopathologic analysis of 70 cases. Arch Pathol Lab Med. 131: 942-6.

${ }^{7}$ Picci, P., 2007. Osteosarcoma (Osteogenic sarcoma) Orphanet J Rare Dis 23, 2-6

${ }^{8}$ Ueda, Y., Roessner, A., Grundmann, E., 1993. Pathological diagnosis of osteosarcoma: the validity of the subclassification and some new diagnostic approaches using immunohistochemistry. Cancer Treat Res 62, 109-24.

${ }^{9}$ Park, S.H., Kim, I., 1999. Small cell osteogenic sarcoma of the ribs: cytological, immunohistochemical, and ultrastructural study with literature review. Ultrastruct Pathol 23, 133-40.

${ }^{10}$ Gadeau AP, Chaulet H, Daret D, Kockx M, Daniel-Lamazière JM, Desgranges C. 2001 Time course of osteopontin, osteocalcin, and osteonectin accumulation and calcification after acute vessel wall injury. $\mathbf{J}$ Histochem Cytochem. 49: 79-86.

${ }^{11}$ Wolf, R.E., Enneking, W.F., 1996. The staging and surgery of musculoskeletal neoplasms. Orthop Clin North Am 27, 473-481.

${ }^{12}$ Paget, J.. 1877. On a form pf chronic inflammationof bones (osteitis deformans). Med Chir Trans 60: $37-$ 63.

${ }^{13}$ Greditzer HG 3rd, McLeod RA, Unni KK, Beabout JW. 1983 Bone sarcomas in Paget disease.

Radiology. 146:327-33.

${ }^{14}$ Smith J, Botet JF, Yeh SD. 1984 Bone sarcomas in Paget disease: a study of 85 patients. Radiology 152: 583-90.

${ }^{15}$ Price CH, Goldie W. 1969 Paget's sarcoma of bone. A study of eighty cases from the Bristol and the Leeds bone tumour registries. J Bone Joint Surg Br. 51: 205-24.

${ }^{16}$ Schajowicz F, Santini Araujo E, Berenstein M. 1983 Sarcoma complicating Paget's disease of bone. A clinicopathological study of 62 cases. J Bone Joint Surg Br. 65: 299-307.

${ }^{17}$ Wick MR, Siegal GP, Unni KK, McLeod RA, Greditzer HG 3rd. 1981 Sarcomas of bone complicating osteitis deformans (Paget's disease): fifty years' experience. Am J Surg Pathol. 5:47-59.

${ }_{18}^{18}$ Reddy, S.V., 2004. Etiology of Paget's disease and osteoclast abnormalities. J Cell Biochem 93, 688-96.

${ }^{19}$ Roodman GD, Windle JJ. 2005 Paget disease of bone. J Clin Invest. 115:200-8.

${ }^{20}$ Hadjipavlou, A., Lander, P., Srolovitz, H., Enker, I.P., 1992. Malignant transformation in Paget disease of bone. Cancer 70, 2802-8.

${ }^{21}$ Mankin, H.J., Hornicek, F.J., 2005. Paget's sarcoma: a historical and outcome review. Clin Orthop Relat Res 438, 97-102.

${ }^{22}$ Vuillemin-Bodaghi, V., Parlier-Cuau, C., Cywiner-Golenzer, C., Quillard, A., Kaplan, G., Laredo, J.D., 2000. Multifocal osteogenic sarcoma in Paget's disease. Skeletal Radiol 29, 349-53.

${ }^{23}$ Mondal, A., Kundu, B., Gupta, S., Biswas, J., 2002. Secondary malignant giant cell tumour of bone--a study of five cases with short review of literature. Indian J Pathol Microbiol 45, 273-5.

${ }^{24}$ Sheen, T.S., Wu, C.T., Hsieh, T., Hsu, M.M., 1997. Postirradiation laryngeal osteosarcoma: case report and literature review. Head Neck 19, 57-62.

${ }^{25}$ Brockstein, B., 2004. Management of sarcomas of the head and neck. Curr Oncol Rep 6, 321-7.

${ }^{26}$ Kumta, S.M., Griffith, J.F., Chow, L.T., Leung, P.C., 1998. Primary juxtacortical chondrosarcoma dedifferentiating after 20 years. Skeletal Radiol 27, 569-73.

${ }^{27}$ Anract, P., Tomeno, B., Forest, M., 1994. [Dedifferentiated chondrosarcoma. A study of 13 clinical cases and review of the literature]. Rev Chir Orthop Reparatrice Appar Mot 80, 669-80.
} 
${ }^{28}$ Bergh, P., Gunterberg, B., Meis-Kindblom, J.M., Kindblom, L.G., 2001. Prognostic factors and outcome of pelvic, sacral, and spinal chondrosarcomas: a center-based study of 69 cases. Cancer 91,1201-12

${ }^{29}$ Björnsson, J., McLeod, R.A., Unni K.K., Ilstrup D.M., Pritchard D.J., 1998. Primary chondrosarcoma of long bones and limb girdles. Cancer 83, 2105-19.

${ }^{30}$ Miller, R.W., Boice, J.D. Jr, Curtis R.E. Bone cancer. In: Schottenfeld D, Fraumeni JF Jr, editors. Cancer epidemiology and prevention. 2nd ed. New York: Oxford University Press; 1996. p. 971-83.

${ }^{31}$ Bovée, J.V., Cleton-Jansen A.M., Taminiau A.H., Hogendoorn P.C.. 2005. Emerging pathways in the development of chondrosarcoma of bone and implications for targeted treatment. Lancet Oncol. 6, 599-607.

${ }^{32}$ Skubitz, K.M., D'Adamo, D.R., 2007. Sarcoma. Mayo Clin Proc 82,1409-32

${ }^{33}$ Gibas, J.F., Huang, P.P., Lee, R.J., McGrath, B., Brooks, J., McKinley, B., Driscoll, D., Kraybill, W.G. 2001. Malignant fibrous histiocytoma: an institutional review. Cancer Invest, 19, 23-7

${ }^{34}$ Mankin HJ, Hornicek FJ. 2005. Diagnosis, classification, and management of soft tissue sarcomas. Cancer Control 12, 5-21.

${ }^{35}$ Hertler, A.A., Moore, J.O., 1987. Sarcomas in the elderly. Clin Geriatr Med 3, 781-801.

${ }^{36}$ Ferrari S, Palmerini E. 2007 Adjuvant and neoadjuvant combination chemotherapy for osteogenic sarcoma. Curr Opin Oncol. 19: 341-6.

${ }^{37}$ Rozeman, L.B., Cleton-Jansen, A.M., Hogendoorn, P.C., 2006. Pathology of primary malignant bone and cartilage tumours. Int Orthop 30, 437-44.

${ }^{38}$ Perbal B, Zuntini M, Zambelli D, Serra M, Sciandra M, Cantiani L, Lucarelli E, Picci P, Scotlandi K. 2008 Prognostic value of CCN3 in osteosarcoma. Clin Cancer Res. 14:701-9.

${ }^{39}$ Nedelcu T, Kubista B, Koller A, Sulzbacher I, Mosberger I, Arrich F, Trieb K, Kotz R, Toma CD. 2008 Livin and Bcl-2 expression in high-grade osteosarcoma. J Cancer Res Clin Oncol. 134:237-44.

${ }^{40}$ Santer, F.R., Bacher, N., Moser, B., Morandell, D., Ressler, S., Firth, S.M., Spoden, G.A., Sergi, C., Baxter, R.C., Jansen-Durr, P., Zwerschke, W., 2006. Nuclear insulin-like growth factor binding protein-3 induces apoptosis and is targeted to ubiquitin/proteasome-dependent proteolysis. Cancer Res 66, 3024-33. ${ }^{41}$ Bacci, G., Ferrari, S., Bretoni, F., Ruggirei, P., Picci, P., Longhi, A., Casadei, R., Fabbri, N., Forni, C., Versari, M., Campanacci, M., 2000. Long-term outcome for patients with nonmetastatic osteosarcoma of the extremity treated at the Istituto Ortopedico Rizzoli according to the Istituto Ortopedico

Rizzoli/osteosarcoma-2 protocol: an updated report. J Clin Oncol 18, 4016-4027.

${ }^{42}$ Fuchs, N., Bielack, S.S., Epler, D., Bieling, P., Delling, G., Korholz, D., Graf, N., Heise, U., Jurgens, H., Kotz, R., Salzer-Kuntschik, M., Weinel, P., Werner, M., Winkler, K., 1998. Long-term results of the cooperative German-Austrian-Swiss osteosarcoma study group's protocol COSS-86 of intensive multidrug chemotherapy and surgery for osteosarcoma of the limbs. Ann Oncol 9, 893-899.

${ }^{43}$ Meyers, P.A., Heller, G., Healey, J., Huvos, A., Lane, J., Marcove, R., Applewhite, A., Vlamis, V., Rosen, G., 1992. Chemotherapy for nonmetastatic osteogenic sarcoma: the Memorial Sloan-Kettering experience. J Clin Oncol 10, 5-15. 


\section{Figure 1}

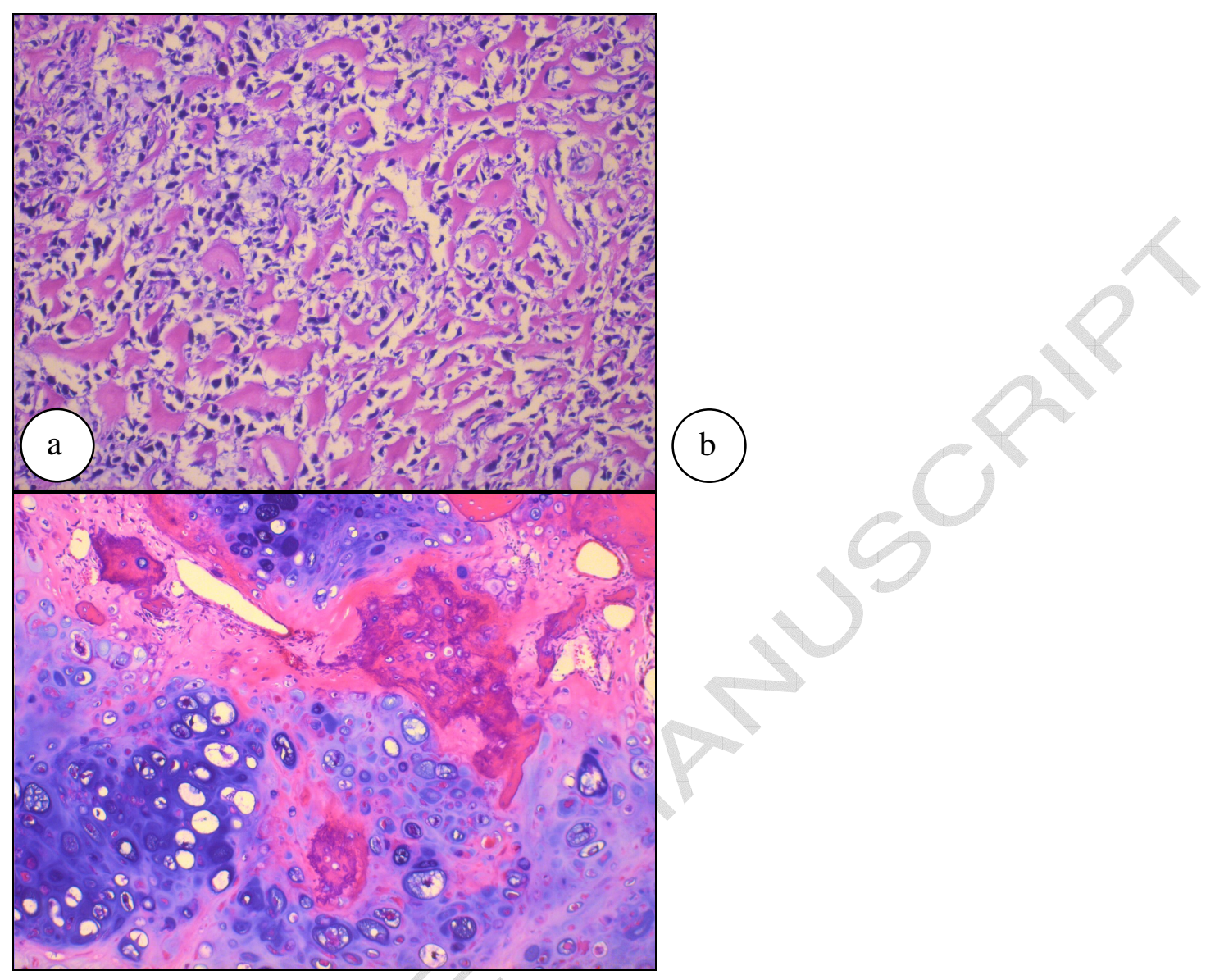




\section{ACCEPTED MANUSCRIPT}
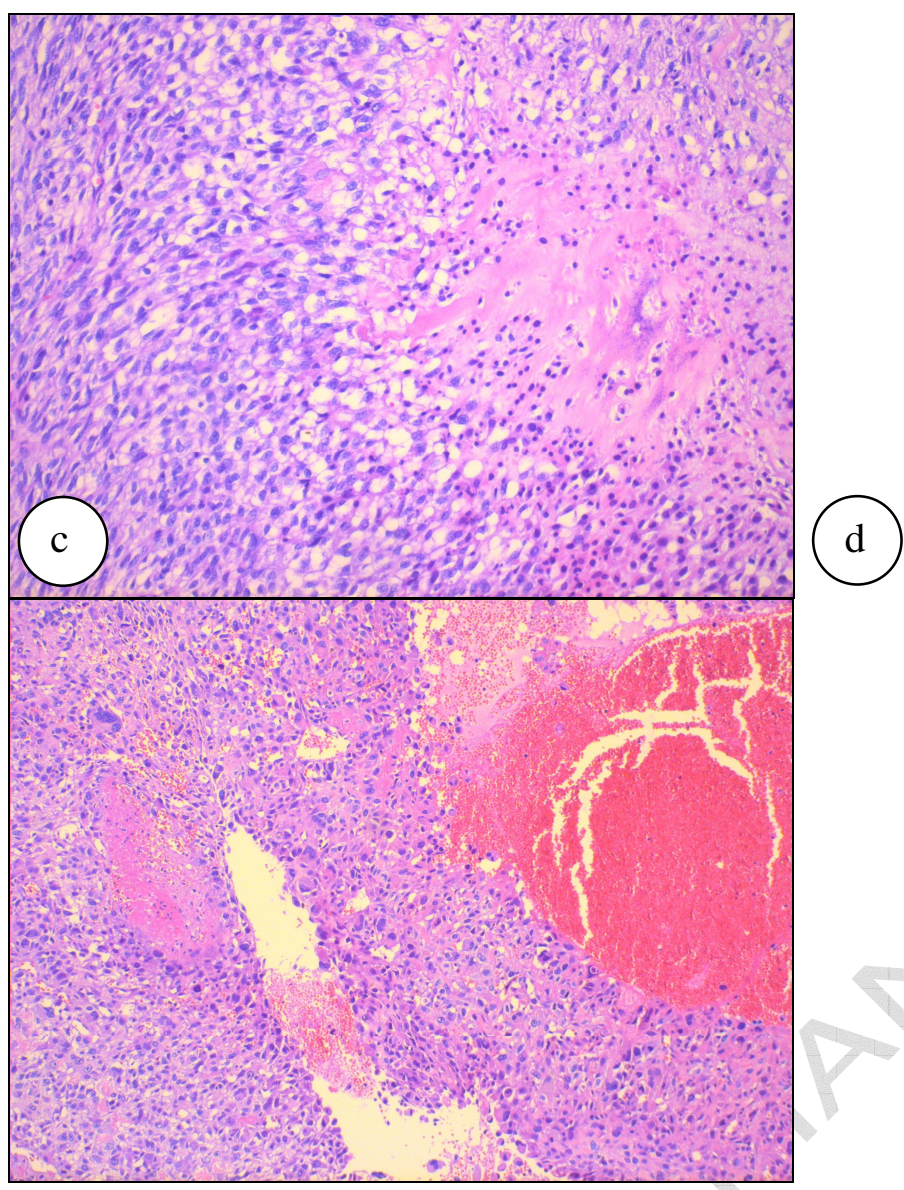

\section{Legend}

Fig. 1a. Osteoblastic osteosarcoma showing the filigree pattern with osteoid, which comprises thin, randomly arborizing lines of osteoid interweaving between osteosarcoma cells. ( $\times 200$, Hematoxylin-Eosin staining).

Fig. 1b. Chondroblastic osteosarcoma with high grade hyaline cartilage that is intimately associated and randomly mixed with non-chondroid elements. $(\times 100$, HematoxylinEosin staining).

Fig. 1c. Fibroblastic osteosarcoma showing high-grade spindle cell malignancy with only minimal amounts of osseous matrix $(\times 200$, Hematoxylin-Eosin staining).

Fig. 1d. Telangectatic osteosarcoma showing blood-filled spaces separated by septa simulating aneurismal bone cyst $(\times 100$, Hematoxylin-Eosin staining). 
Table 1. Staging of Osteogenic Sarcomas

\begin{tabular}{llll}
\hline Stage & Grade & Site & Metastasis \\
\hline IA & Low & Intra-compartmental & No \\
IB & Low & Extra-compartmental & No \\
IIA & High & Intra-compartmental & No \\
IIB & High & Extra-compartmental & No \\
IIII & Any & Any & Regional or distant \\
\hline
\end{tabular}

\section{Notes:}

This system based on: tumour grade ( $\mathrm{I}=$ low grade; $\mathrm{II}=$ high grade), tumour extension ( $\mathrm{A}=$ intraosseous involvement only; $\mathrm{B}=$ intra- and extraossseous extension); and presence of distant metastases (III). Patients with localized high grade osteosarcoma may have stage IIA or IIB. The presence of metastatic disease, regardless the extent of the primary lesion, represents a stage III disease. 